\title{
НОРМАТИВНОЕ СОДЕРЖАНИЕ НЕФТЕПРОДУКТОВ И ФЕНОЛОВ В СТОЧНЫХ ВОДАХ ОЧИСТНЫХ СООРУЖЕНИЙ СЕВЕРНОЙ ЖЕЛЕЗНОЙ ДОРОГИ
}

\begin{abstract}
А.С. Герасимов, А.А. Мельников
Ярославский государственный педагогический университет ии. К. Д. Уиинского, Россия

Поступила в редакцию 5 сентября 2018 г.

Аннотация: Цель работы - сопоставить функциональное состояние сотрудников «Северной железной дороги» (СЖД) с показателями содержания нефтепродуктов и фенолов в составе сточных вод предприятий. Изучен уровень нефтепродуктов и в пробах сточной воды фенолов (всего 150 проб) на двадцати предприятиях полигона СЖД с помощью анализатора жидкости «Флюорат 02-2М» флуориметрическим методом. Функциональное состояние определяли у 150 специалистов девятнадцати предприятий всего полигона СЖД общепринятыми методами. Результаты. Превышений рекомендованных уровней нефтепродуктов и фенолов в составе сточных вод на всех предприятиях СЖД не выявлено. Однако уровень нефтепродуктов существенно колебался (ANOVA, p=0,01): минимальные величины выявлены на станциях г. Ярославля, пос. Вычегодского, г. Котласа и пос. Кулоя, а повышенные - на станциях г. Инты, г. Воркуты и пос. Коноша. Уровень фенолов различался между станциями СЖД ( $\mathrm{p}=0,01)$ : минимальные величины отмечены на станции Ярославль-Главный, а максимальные - на станции г. Сосногорск.
\end{abstract}

Ключевые слова: нефтепродукты, фенолы, сточные воды, экология.

\section{Normative content of oil products and phenols in wastewaters of the Northern railway treatment facilities}

\section{A.S. Gerasimov, A. A. Melnikov}

\begin{abstract}
The purpose of the work was to compare the functional state of the Northern railway employees (SZD) with the indicators of petroleum products and phenols in wastewater. We investigated the level of petroleum products and in samples of waste water of phenols (total 150 samples) twenty companies of the polygon of the SZD using the fluid analyzer «Fluorat $02-2 \mathrm{M}$ » fluorimetric method. The functional state (arterial pressure (BP), body mass index, adaptive potential of blood circulation) was determined in 150 specialists of nineteen enterprises of the entire range by conventional methods. Results. No exceedances of the recommended levels of oil products and phenols in wastewater were detected at all enterprises of the Russian Railways. However, the level of oil fluctuated significantly (ANOVA, $p=0.01$ ): the minimum value detected at the stations of the city of Yaroslavl, the settlement of Vychegodskiy, Kotlas and the village of Kuloy, and elevated - stations, Inta, Vorkuta and the settlement of Konosha. The phenols level differed between the stations of SZD $(p=0.01)$ : the minimum values were marked at the station Yaroslavl-Main, and the maximum - at the station Sosnogorsk.
\end{abstract}

Key words: oil products, phenols, waste waters, ecology.

\section{ВВЕДЕНИЕ}

В настоящее время проблема охраны окружающей среды является крайне актуальной $[6,8]$. Действительно, на сегодняшней день мы имеем мощные промышленные предприятия, которые не только производят необходимые людям блага, но и наносят огромный ущерб природе и здоровью человека. Исключением не являются «Российские

() Герасимов А.С., Мельников А.А., 2019 железные дороги» - крупнейшая компания России по пассажиро- и грузоперевозкам. В состав железной дороги входит множество предприятий, которые наносят существенный ущерб природе и, следовательно, здоровью человека. Каждый день предприятия дороги сбрасывают огромное количество воды, загрязненной токсичными веществами, превышение концентрации которых является неблагоприятным фактором [4]. Такая же картина 
наблюдается с выбросами токсичных веществ в атмосферу, почву. Однако РЖД активно борется с негативным воздействием на природу и человека, создавая центры охраны окружающей среды [5], которые обеспечивают производственный экологический контроль за предприятиями дороги; устанавливает на свои предприятия современные очистные сооружения, которые призваны улучшить экологическую обстановку на железной дороге. Несмотря на все эти усилия, существует проблема загрязнения окружающей среды нефтепродуктами различных фракций, а также соединениями фенолов $[1,4]$. К нефтепродуктам относятся смеси углеводородов, индивидуальные химические соединения, получаемые из нефти и нефтяных газов, различные виды топлива: бензин, дизельное топливо, керосин [3]. Фенолы - это гидроксильные производные ароматических углеводородов, в молекулах которых функциональные группы связаны с ароматическим ядром [7]. Эти соединения наносят существенный вред не только природе, но и функциональному состоянию сотрудников железной дороги. В данной статье мы оценили и сопоставили функциональное состояние сотрудников «Северной железной дороги» с показателями содержания нефтепродуктов и фенолов в составе сточных вод предприятий, непосредственно контактирующих с выбросами предприятий СЖД.

\section{МАТЕРИАЛЫ И МЕТОДЫ}

В работе изучено содержание нефтепродуктов и фенолов в пробах сточных вод на 20 предприятиях полигона «Северной железной дороги». Анализ нефтепродуктов и фенолов выполнялся с применением методик измерений массовых концентрации нефтепродуктов и фенолов в пробах природных, питьевых и сточных вод флуориметрическим методом на анализаторе жидкости «Флюорат02» (стандарты ПНД Ф 14.1:2:4.128-98 и ПНД Ф 14.1:2:4.182-02 для нефтепродуктов и фенолов соответственно).

На добровольной основе обследованы специалисты ( $\mathrm{n}=150)$, работающие на следующих предприятиях СЖД: ст. Ярославль-Главный, Лаборатория центра охраны окружающей среды (НЦОПэл) $(\mathrm{n}=4)$; ст. Печора, Путевая машинная станция по ремонту и эксплуатации путевых машин (ПМС-319) $(\mathrm{n}=6)$; ст. Инта, Северная дирекция тепловодоснабжения (Сев ДТВ) $(\mathrm{n}=6)$; ст. Инта ПМС-324 $(\mathrm{n}=5)$; ст. Воркута Сев ДТВ $(\mathrm{n}=6) ;$ ст. Воркута, эксплуатационное вагонное депо (ВЧДЭ-16) $(\mathrm{n}=6)$; ст. Мульда Сев ДТВ $(\mathrm{n}=8)$; ст. Коноша ПМС-56 (n=9); ст. Коноша, Дистанция пути (ПЧ-19) $(\mathrm{n}=10)$; ст. Коноша Дирекция тепловодоснабжения (ДТВС) $(\mathrm{n}=11)$ ст. Кулой, (ДТВС) $(\mathrm{n}=9)$; ст. Кулой, Дистанция гражданских сооружений $($ НГЧ-7) $(\mathrm{n}=7)$; ст. Сольвычегодск ДТВС $(\mathrm{n}=10)$; ст. Сольвычегодск НГЧ-7 ( $=10)$; ст. Котлас ДТВС $(\mathrm{n}=9)$; ст. Сосногорск ДТВС $(\mathrm{n}=8)$; ст. Сосногорск НГЧ-8 $(\mathrm{n}=7) ;$ ст. Микунь ДТВС $(\mathrm{n}=7) ;$ ст. Керки ДТВС $(n=6)$; ст. Княжпогост ДТВС $(n=6)$.

В условиях рабочего места в утренние часы рабочей смены в состоянии функционального покоя стандартными методами определены основные функциональные показатели здоровья у специалистов предприятий СЖД.

\section{СТАТИСТИКА}

Для выявления различий по уровням нефтепродуктов, фенолов и физиологических показателей между предприятиями СЖД использован однофакторный дисперсионный анализ. Сравнение показателей между отдельными предприятиями выполнено с помощью апостериорного критерия наименьшей значимой разности. Для выявления взаимосвязей между показателями использована ранговая корреляция Спирмена.

\section{РЕЗУЛЬТАТЫ}

Показатели нефтепродуктов и фенолов в сточных водах. На полигоне СЖД средняя концен-

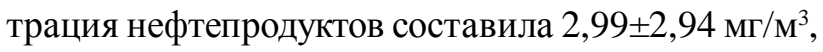

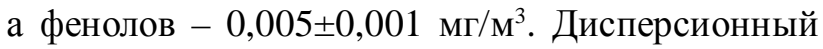
анализ выявил различия по уровню фенолов ( $<<0,0001$, рис. 1) и нефтепродуктов ( $<<0,0001$, рис. 2) в пробах сточных вод между предприятиями СЖД. Однако на всех предприятиях уровни нефтепродуктов и фенолов в сточных водах были значительно ниже рекомендованных норм (10 мг/м ${ }^{3}-$

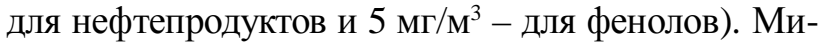
нимальные концентрации нефтепродуктов и фенолов отмечены на станции Ярославль - Главный НЦОПэл, а максимальные концентрации нефтепродуктов и фенолов на станции Коноша - ПЧ-19 и на станции Сосногорск - НГЧ-8 соответственно.

Функииональные показатели здоровья. Корреляционный анализ показал, что основные отклонения состояния здоровья у сотрудников Северной железной дороги не связаны с содержанием фенолов и нефтепродуктов.

\section{ОБСУЖДЕНИЕ}

Проведенное исследование позволило установить, что 1) уровни фенолов и нефтепродуктов существенно различается на предприятиях СЖД, однако они находятся в пределах допустимой санитарной нормы и 2) у $35 \%$ специалистов, ра- 


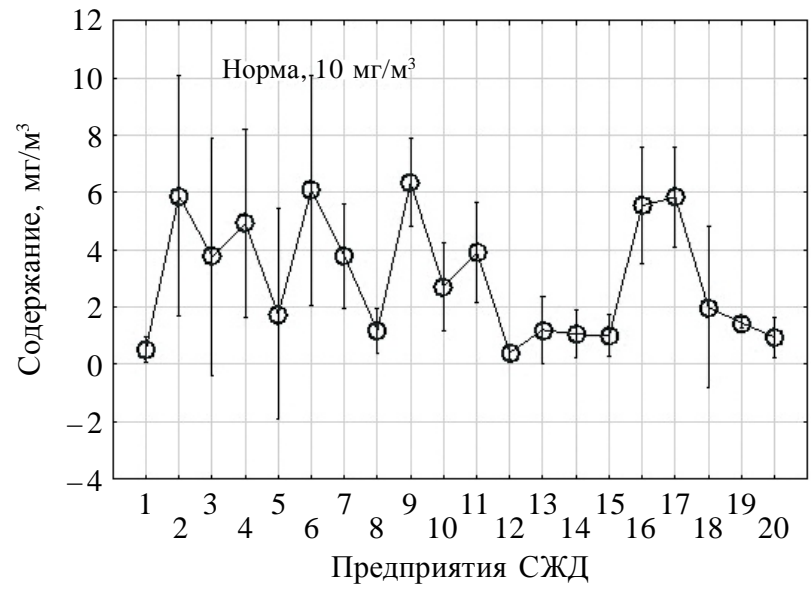

Puc. 1. Содержание нефтепродуктов в сточной воде на предприятиях СЖД (М \pm Дов. Инт) $(\mathrm{p}<0,001)$ Примечание: 1 - Ярославль-Главный, НЦОПэл; 2 - Печора, ПМС-319; 3 - Инта, Сев ДТВ; 4 - Инта, ПМС-324; 5 - Воркута Сев ДТВ; 6 - Воркута, ВЧДЭ-16; 7 - Мульда, Сев ДТВ; 8 - Коноша ПМС-56; 9 - Коноша ПЧ-19; 10 - Коноша, ДТВС; 11 - Кулой, ДТВС; 12 - Кулой, НГЧ-7; 13 - Сольвычегодск, ДТВС; 14 - Сольвычегодск, НГЧ-7; 15 - Котлас, ДТВС; 16 - Сосногорск, ДТВС; 17 - Сосногорск, НГЧ-8; 18 - Микунь, ДТВС; 19 - Керки, ДТВС; 20 - Княжпогост, ДТВС

ботающих на обследованных предприятиях СЖД, отмечается повышенное САД, а у $64 \%$ - повышенный ИМТ.

Различия между предприятиями по уровню нефтепродуктов и фенолов можно объяснить следующими причинами. Во-первых, это может быть обусловлено различными темпами производства. Станции различаются по своему пассажиропотоку и грузообороту. Загруженность предприятий неодинакова [2], следовательно, у разных предприятий идет неодинаковый сброс сточной воды, а значит, концентрация нефтепродуктов и фенолов будет весомо различаться. Например: самая высокая концентрация нефтепродуктов зафиксирована на станции Коноша на предприятии ПЧ-19. Коноша является одной из узловых станции на СЖД, где существует высокая загруженность. Во-вторых, различия в загрязнении, очевидно, связаны с эффективностью работы очистных сооружений. Все предприятия на полигоне СЖД снабжены очистными сооружениями. Но различная эффективность их работы, условия эксплуатации, могут влиять на качество сбрасываемой воды в коллектор. Действительно, одна из наибольших станция СЖД - Ярославль-Главный, отличается большим пассажирои товарооборотом, однако уровень фенолов на этом

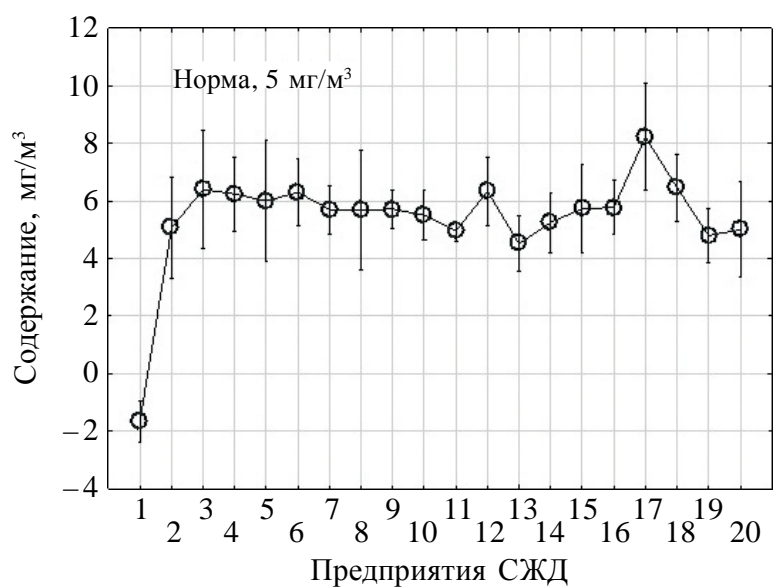

Puc. 2. Содержание фенолов в сточной воде на предприятиях СЖД (М \pm Дов. Инт) (p <0,001). Примечание: 1 - Ярославль-Главный, НЦОПэл;

2 - Печора, ПМС-319; 3 - Инта, Сев ДТВ; 4 - Инта,

ПМС-324; 5 - Воркута Сев ДТВ; 6 - Воркута, ВЧДЭ-16; 7 - Мульда, Сев ДТВ; 8 - Коноша ПМС-56; 9 - Коноша ПЧ-19; 10 - Коноша, ДТВС; 11 - Кулой, ДТВС; 12 - Кулой, НГЧ-7; 13 - Сольвычегодск, ДТВС; 14 - Сольвычегодск, НГЧ-7; 15 - Котлас, ДТВС; 16 - Сосногорск, ДТВС; 17 - Сосногорск, НГЧ-8; 18 - Микунь, ДТВС; 19 - Керки,ДТВС; 20 - Княжпогост, ДТВС

предприятии минимальный. Таким образом, большее значение имеет эффективность работы очистных сооружений.

Установлено, что на предприятиях превышений по уровням нефтепродуктов и фенолов нет. Согласно «Постановлению от 29 июля 2013 года N 644 «Об утверждении Правил холодного водоснабжения и водоотведения и о внесении изменений в некоторые акты Правительства Российской Федерации» концентрация нефтепродуктов в сточной воде должна быть не более $10 \mathrm{mг} / \mathrm{M}^{3}$, а фенолов - не более 5 мг/Mㄹ. Поскольку на полигоне СЖД была проведена комплексная модернизация железнодорожного полотна, то отпала необходимость обрабатывать железнодорожные пути растворами, содержащими соединения нефтепродуктов и фенолов. Для предотвращения превышений рекомендуемых нормативов по вышесказанным показателям необходимо содержать очистные сооружения в удовлетворительном состоянии, проводить постоянную чистку колодцев и систем водоотведения.

Корреляционный анализ показал, что изменения в здоровье сотрудников СЖД не были связаны с содержанием фенолов и нефтепродуктов в сточных водах на данных предприятиях. 


\section{ЗАКЛЮЧЕНИЕ}

В содержании нефтепродуктов и фенолов в сточных водах на предприятиях СЖД отмечаются существенные колебания, однако они находятся в пределах санитарных допустимых норм, отражая эффективность работы очистных сооружений. Отклонения в функциональных показателях здоровья, выявленные у специалистов СЖД, не связаны с уровнем загрязнения сточных вод на данных предприятиях. Отсутствие превышений концентраций нефтепродуктов и фенолов на полигоне СЖД объясняется наличием большого количества очистных сооружений, их удовлетворительным состоянием и эффективной работой. Для предотвращения негативного воздействия рабочей среды необходимо поддерживать состояние очистных сооружений на должном уровне, а работникам принимать меры личной безопасности и профилактики заболеваний.

\section{СПИСОК ЛИТЕРАТУРЫ}

1. Богатушин А. В. Пособие для поступающих в вузы и студентов по органической химии / А. В. Богатушин, Е. В. Сальников, Н. И. Новожилова; под общ. ред. Г. А. Урванцевой. - 5-е изд. - Москва; Ярославль, 2009. $-67 \mathrm{c}$.

2. Бродский И. Экотоксикология нефти и здоровье человека [Электронный ресурс] / И. Бродский. - URL : http://www.referatsochinenie.ru/add/ekologiya i ohrana prirody/ekotoksikologiya_nefti_i_zdorove_cheloveka.html.

3. Иларионов С. А. Экологические аспекты восстановления нефтезагрязненных почв / С. А. Иларионов. Екатеринбург : Уральское отделение РАН, 2004. - 192 с.

4. Локтионова Е. Г. Мониторинг загрязнения фенолами, нефтепродуктами и синтетически поверхностноактивными веществами водоемов г. Астрахани [Электронный peсурс] / Е. Г. Локтионова, Г. В. Болонина, Л. В. Яковлева. - URL: http://vestnik.osu.ru/2012 6/26.pdf.

5. Приказ ОАО «Российские железные дороги» от 21 окт. 2010 г. № 165 О структурных преобразованиях на Северной железной дороге. - URL : //http://scbist.com/ scb/uploaded/docs/2010/oktyabr-2010/6016-prikaz-oaorzhd-ot-21-10-2010-n-165.htm (дата обращения : 06.06.2019)

Герасимов Александр Сергеевич

аспирант кафедры физического воспитания Ярославского государственного педагогического университета им. К.Д. Ушинского, г. Ярославль, Е-mail: Alex Prorok.92@mail.ru

Мельников Андрей Александрович доктор биологических наук, профессор, зав. кафедрой физического воспитания Ярославский государственный педагогический университет им. К. Д. Ушинского, г. Ярославль, E-mail: meln1974@ yandex.ru
6. Природопользование : учебник для вузов / под ред. Э. А. Арустамова. - Москва : Дашков и К ${ }^{\circ}, 2000 .-284$ с.

7. Fernandes H. L. Simultaneous determination of methanol and ethanol in gasoline using nir spectroscopy: effect of gasoline composition / H. L. Fernandes, C. Pasquini, J. J. R. Rohwedder // Talanta. - 2008. - № 3. P. 804-810.

8. Gol'din V. D. Fundamental and a protection applied problems of environmental / V. D. Gol'din, P. M. Nagorskii // Physical-Mathematical Problems of Enviromental Protection. - 1995. - № 1. - P. 133.

\section{REFERENCES}

1. Bogatushin A. V. Posobie dlya postupayushchikh v vuzy i studentov po organicheskoy khimii / A. V. Bogatushin, E. V. Sal'nikov, N. I. Novozhilova; pod obshch. red. G. A.Urvantsevoy. - 5-e izd. - Moskva; Yaroslavl', 2009. $67 \mathrm{~s}$.

2. Brodskiy I. Ekotoksikologiya nefti i zdorov'e cheloveka [Elektronnyy resurs] / I. Brodskiy. - URL : http:// www.referatsochinenie.ru/add/ekologiya i ohrana_prirody/ ekotoksikologiya_nefti_i_zdorove_cheloveka.html.

3. Ilarionov S. A. Ekologicheskie aspekty vosstanovleniya neftezagryaznennykh pochv / S. A. Ilarionov. - Ekaterinburg : Ural'skoe otdelenie RAN, 2004. - $192 \mathrm{~s}$.

4. Loktionova E. G. Monitoring zagryazneniya fenolami, nefteproduktami i sinteticheski poverkhnostno-aktivnymi veshchestvami vodoemov g. Astrakhani [Elektronnyy resurs] / E. G. Loktionova, G. V. Bolonina, L. V. Yakovleva. - URL: http://vestnik.osu.ru/2012_6/26.pdf.

5. Prikaz OAO «Rossiyskie zheleznye dorogi» ot $21 \mathrm{okt}$. 2010 g. № 165 O strukturnykh preobrazovaniyakh na Severnoy zheleznoy doroge. - URL : //http://scbist.com/scb/ uploaded/docs/2010/oktyabr-2010/6016-prikaz-oao-rzhdot-21-10-2010-n-165.htm (data obrashcheniya : 06.06.2019)

6. Prirodopol'zovanie : uchebnik dlya vuzov / pod red. E. A. Arustamova. - Moskva : Dashkov i K ${ }^{\circ}, 2000 .-284$ s.

7. Fernandes H. L. Simultaneous determination of methanol and ethanol in gasoline using nir spectroscopy: effect of gasoline composition / H. L. Fernandes, C. Pasquini, J. J. R. Rohwedder // Talanta. - 2008. - № 3. - P. 804-810.

8. Gol'din V. D. Fundamental and a protection applied problems of environmental / V. D. Gol'din, P. M. Nagorskii // Physical-Mathematical Problems of Enviromental Protection. - 1995. - № 1. - P. 133.

Gerasimov Aleksandr Sergeevich

Postgraduate student of the Department of physical education, Yaroslavl State Pedagogical University named after K.D. Ushinsky, Yaroslavl, E-mail:Alex_Prorok.92@mail.ru

Melnikov Andrey Aleksandrovich

Doctor of Biological Sciences, Professor, Head of the Department of physical education, Yaroslavl State Pedagogical University named after K. D. Ushinsky, Yaroslavl, E-mail: meln1974@yandex.ru 